\title{
The Community Size Effect on the Techno-Economic Performance of Solar District Heating Systems
}

\author{
Mohamed Hany Abokersh \\ Departament d'Enginyeria \\ Mecànica \\ Universitat Rovira i Virgili \\ Av. Països Catalans 26, 43007 \\ Tarragona, Spain \\ Mohamed.Abokersh@urv.cat
}

\author{
Manel Vallès \\ Departament d'Enginyeria \\ Mecànica \\ Universitat Rovira $i$ Virgili \\ Av. Països Catalans 26, 43007 \\ Tarragona, Spain \\ Manel.Valles@urv.cat
}

\author{
Luisa F.Cabeza \\ GREiA Research Group, \\ INSPIRES Research Centre \\ Universitat de Lleida \\ Pere de Cabrera s/n, 25001 \\ Lleida, Spain \\ luisaf.cabeza@udl.cat
}

\author{
Dieter Boer \\ Departament d'Enginyeria \\ Mecànica \\ Universitat Rovira $i$ Virgili \\ Av. Països Catalans 26, 43007 \\ Tarragona, Spain \\ Dieter.Boer@urv.cat
}

\begin{abstract}
The Solar assisted district heating system (SDHS) is a promising path to accelerate the sustainable movement toward clean energy production in order to solve the challenges of the energy crisis and climate change. However, in real conditions the SDHS is often suffering from a mismatch between the predict and actual performance. This mismatch promotes a high variation in quantifying the SDHS benefits at different urban community sizes. This article traces the techno-economic performance of SDHS through an optimization framework using dynamic TRNSYS for simulations and a genetic algorithm for optimization. The SDHS application is performed for a residential community of 10,25 and 50 buildings located in Madrid to evaluate its techno-economic feasibility in covering the heating demand of these communities. The larger communities provided noticeable cost-benefits when aiming for high performance, where the cost objective is between 73.1:149.1 Euro/MWh for the community of 10 and it can be improved up to $27.5 \%$ and $\mathbf{4 1 . 6 \%}$ for community sizes of 25 and 50 buildings, respectively. While in terms in the payback period, it can be reduced up to 29 years for the community size of $\mathbf{5 0}$ buildings. The solar fraction can achieve up $99 \%$ with a seasonal storage tank efficiency of $81 \%$ at the community size of 50 buildings.
\end{abstract}

Keywords - Solar assist district heating system, Life cycle cost, Life cycle assessment, Multi-objective optimization, Urban community

\section{INTRODUCTION}

The significant contribution to the European energy demand is from the heating of the building where the residential buildings consume $63 \%$ of this energy [1]. Moreover, more than $75 \%$ of residential energy consumption is utilized for space and domestic hot water heating [2]. Production of energy is very harmful to the environment and using renewable sources of energy can help in reducing its environmental impacts. Hybrid solar heating or biomass are typical examples of such systems [3]. Solar energy is the largest source of energy, but it is affected by seasonal variations and diurnal. Diurnal is a critical problem; it creates a mismatch between the time of production and demand for energy. In addition, the energy storage devices are very costly. However, the use of thermal energy storage in hot water tanks helps in removing the mismatch during the heating applications. Moreover, it is also helpful for the mismatch of solar problems [4]. The real problem is that the demand for heat generation is highest when the production of energy is the lowest. This mismatch in the demand and supply of energy during winters affect the solar energy systems performance. The difference in the availability of solar energy in summers and winters increase in the countries that are away from the equator. Seasonal thermal energy storage can solve the issue of seasonal variation [5]. The seasonal storage allows the storage of energy in the season of high production. The stored energy can be used in the seasons of peak demand. With the development of several storage mechanisms, including the latent heat storage chemical storage, and sensible heat storage systems, the sensible heat storage is more reliable. This type of system works on the capability of temperature change of high heat capacity materials [6]. Some of the vital sensible energy storage devices are [7]:

- $\quad$ Aquifer thermal energy storage (ATES)

- Hot water thermal energy storage (TTES)

- Water pit thermal energy storage (PTES)

- Borehole thermal energy storage (BTES)

Seasonal thermal energy storage devices are usually used in solar communities where a specific amount of heating demand is to be fulfilled with solar energy. Solar communities began to develop after the energy crisis of the 1970s [8]. Most of these communities are in Germany [9], Denmark, Sweden, and other major countries of Europe [10]. In some solar communities, TTES is used. In recent studies, water-based storage tanks are also being considered [11]. Currently, Denmark is trying to design large solar district heating systems (SDHS) that depend on the water pit storage [7]. In Germany, the Neckarsulm community was developed in 1997 that comprises of a gym, school, shopping center and 200 housing apartments. A BTES of $63,000 \mathrm{~m}^{3}$ capacity is installed. A heat pump along with the gas boiler is set up for the backup. Similarly, the Crailsheim community was developed based on a 37,500 $\mathrm{m}^{3}$ BTES in 2007. This community contains a gym, school, and 260 housing apartments [12]. This community was backed up by the district heat pump. The storage capacity of the Crailsheim is lesser than Neckarsulm but the solar collectors installed in Crailsheim $\left(7500 \mathrm{~m}^{2}\right)$ are comparatively larger than Neckarsulm $\left(5670 \mathrm{~m}^{2}\right)$. There are small solar communities as such as the Attenkirchen solar community that only consists of 30 homes [13]. An 
underground water tank that is surrounded by $10,500 \mathrm{~m}^{3}$ BTES is used in this community. The same design was copied for the sole Finnish solar community that was developed in Kerava [14]. However, the community was dismantled and converted back to the SDHS. Drake Landing Solar Community (DLSC) in Canada is the most famous solar community. It became functional in 2008 [15]. It consists of $2300 \mathrm{~m}^{2}$ solar collectors and two $34,000 \mathrm{~m}^{3}$ BTES systems. It supplies heat to 52 houses. The Drake Landing community meets $98 \%$ of the total demand for space heating, while the Anneberg system can reach $60 \%$ of the total heating demand for space and water .On the other side, Braedstrup SDHS in Denmark has a 19,000 $\mathrm{m}^{3}$ BTES system and a solar thermal area of $18,600 \mathrm{~m}^{2}$.[16]. With few exceptions, the real performance of the SDHS has rarely met with the estimated or predicted results where the monitored performance in terms of the solar fraction fails below the estimated results in the Neckarsulm and drake communities [17]. This performance variation increases with the solar community sizes since each community has different short-term and long-term energy storage as well as different solar collector areas, different auxiliary heating systems and different environmental conditions. Therefore, the reason behind different solar fractions of different communities as most of the samples correlation is far from clear, which implies other parameters are also very important for determining the performance of a solar community.

In this article, the techno-economic optimization of a solar community is studied under the effect of community size with considering for the same equipment sizing. The high seasonal variability of solar energy as well its share to cover the heating demand represent significant techno-economic challenges. The literature does not account for the total system optimizations. The study focuses on Madrid because Madrid does not have any established solar community. The life-cycle cost and energy performance are the objectives of the study, in which it is carried out by considering the multi-objective optimization that contains generic algorithms. Different configurations of energy production and energy storage are reviewed for increasing the efficiency of the system. In simple words, the objective of the study is to analyze the effects of community size and finding out the parameters that affect the system design.

\section{SYSTEM METHODS EVALUATION}

\section{A. Energy system details and modelling}

A virtual residential community is studied that contained a specified solar system along with the district heat system (SDHS). TRNSYS 18 software is used for the modelling of the residential community. Solar collector field, seasonal storage tank (SST), and domestic hot water storage tanks (DHWT) are the major components of the SDHS. The solar collector field can be installed on the roofs of the residential buildings or on the grounds that are near the energy storage.

The SST is a large water tank that is half-buried in the ground, and it is used for the storage of the heated energy for extended periods. The SST can be used for addressing the energy demands in the winter season. On the other side, THE

This project has received funding from the European Union's Horizon 2020 research and innovation programme under the Marie Skłodowska-Curie grant agreement No. 713679 and from the Universitat Rovira i Virgili (URV).
DHWT is a small-scale tank that provides heat in a daily base. Auxiliary natural gas boiler heaters $(\mathrm{BH})$ are utilized for covering the mismatch between the demand and supply of energy. Fig. 1 shows a schematic diagram of the SDHS.

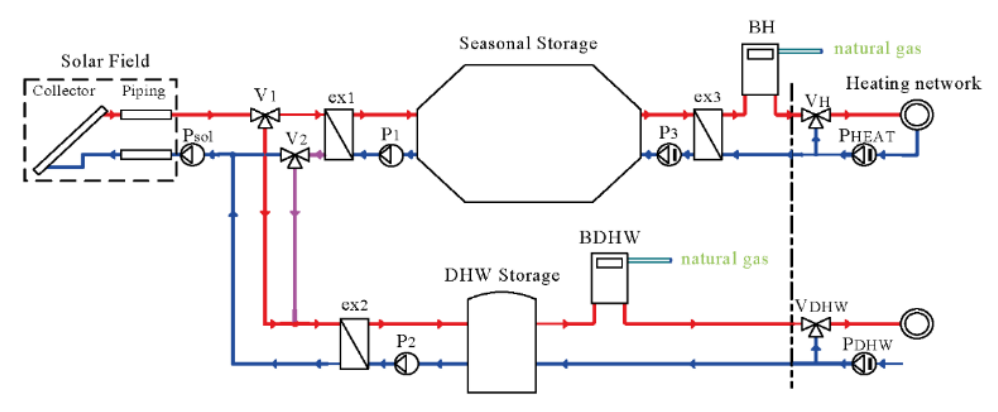

Fig. 1. Simple schematic representation for the SDHS [19]

TRNSYS 18 [18] is a simulation software that is used for studying the dynamic behavior of the prescribed SDHS. The software provides a realistic simulation of the plant. The model is developed based on the model of Tulus et al.[19]. Small modifications in the model were done to cover the realistic situations for the DHW distribution network.

In TRNSYS, interconnected blocks make the flow diagram of the system. Every component of the network has three information blocks. Two blocks are for input and output variables. While the third block defines the parameters of the component. Because of the limited computational power, the problem is solved for three years, and then the results were extrapolated for the plant lifetime.

There are various components in the TRNSYS simulation model. These components are flat plate solar collector (Type 1) with 0.817 optical efficiencies, SST (Type 4) with fixed inlets and construction materials specification selected based on Friedrichshafen project [12]. While the DHW tank is specified with a heat loss coefficient of $0.3125 \mathrm{~W} / \mathrm{m}^{2} \mathrm{~K}$. The system contains counter flow heat exchangers (Type 5) that have 3931 $\mathrm{W} / \mathrm{m}^{2} \cdot \mathrm{K}$ overall heat transfer coefficient and $93 \%$ efficient auxiliary heaters (Type 5). In addition to, inlet and outlet pipe ducts (Type 31), single-speed circulation pumps (Type 3d), three-way valves (Type 11), soil temperature profile (Type 77), meteorological TMY2 data files (Type 15), and time-dependent forcing function (Type 9).

\section{B. Thermal performance}

The final demand for imported offsite energy can be examined for the evaluation of the solar community performance. However, some other indicator can also be useful for comparing case studies. Solar fraction (SF) is a common indicator that describes the fraction of energy demand met by solar energy. In this study, the solar energy system is supported by an auxiliary heater, which means that energy can be taken out of the SDHS even if it has not been charged with active solar systems. Thus, the SF is calculated directly through determining the total energy consumption due to using the auxiliary heaters 
for heating and domestic hot water purposes and assuming all remaining energy was generated by solar energy.

$$
\begin{aligned}
& S . F_{S H}=1-\frac{\sum_{i=1}^{n} \dot{Q}_{\text {Aux }-B H}}{Q_{\text {Heating load }}} \\
& S . F_{D H W}=1-\frac{\sum_{i=1}^{n} \dot{Q}_{\text {Aux }-B D H W}}{Q_{D H W \text { load }}}
\end{aligned}
$$

Where $S . F_{S H}$ and $S . F_{D H W}$ are the solar fraction in the space heating (SH) circuit and Domestic hot water (DHW) circuit, respectively. While $\dot{Q}_{A u x-B H}$ and $\dot{Q}_{A u x-B D H W}$ are the duty of

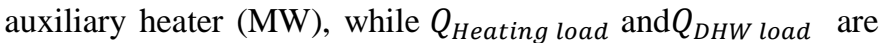
the total heating energy and domestic hot water used in the buildings.

Another key factor of the SDHS is the efficiency of the SST which can be defined simply as the ratio of annual energy losses throughout the SST vs the heat transfer rate through the heat exchangers ex1.

$$
\eta_{S S T}=1-\frac{\int_{0}^{t} \dot{Q}_{S S T \text { loss }}}{\int_{0}^{t} \dot{Q}_{H E_{1}}}
$$

This efficiency depends on another thermal characterization of the SST which is the thermal heat losses throughout the SST, and it can be evaluated based on heat losses through the top, sideways, and bottom of the storage. The thermal heat loss through these surfaces depends on the construction material, the insulation material, the ground properties, and the height to diameter ratio. While $h_{\text {conv }}$ which is the convective heat transfer coefficient is considered $10 \mathrm{~W} / \mathrm{m}^{2} \cdot \mathrm{K}$. Moreover, $\lambda_{G}$ which is the ground thermal conductivity is considered $3 \mathrm{~W} / \mathrm{m} \cdot \mathrm{K}$.

\section{Economic performance}

The 40-year life cycle cost (LCC) of the SDHS in its net present value format is utilized as an economic indicator. The LCC generally includes the initial cost (IC), operational cost (OC), maintenance cost (MC), and replacement cost (RC), as expressed in Eq. (4).

$N P C=I C+O C+M C+R C$

In this study, the initial equipment cost was determined by Eqs. (5), in which the upfront costs of the solar collector, the water storage tanks and the auxiliary heater equipment were determined.

$$
I C=\left(1+\alpha_{C F}\right) \sum_{k}\left(P C E_{k} \cdot F B M_{k}\right)
$$

where $P C E_{k}$ represents the initial capital cost of purchased unit $k, F B M_{k}$ is the bare module factor, which states for the installation and transportation cost of unit $k$, and $\alpha_{C F}$ donates for the contingency factor.

While the operational and maintenance cost state the annual maintenance cost of equipment in addition to their relative energy consumption throughout the system lifetime. As it can be expressed as following:

$$
C_{O}=C_{M} P W F_{M}+C_{P} P W F_{P}+C_{A U X} P W F_{A U X}
$$

where the $C_{M}, C_{P}$, and $C_{A U X}$ donate for the annual maintenance cost, the recirculation pumps, and the auxiliary heater consumption cost. While $P W F$ tends for the time value of the money with consideration for the inflation rate $(i)$ and discount rate $(d)$ throughout the proposed system lifetime.

The replacement cost in this study states for the depreciation associate with the equipment including the solar collector, the domestic hot water storage tank, and auxiliary heaters besides other equipment such as recirculating pumps and heat exchangers and it can be expressed as following.

$$
C_{R}=P V F_{n} \sum_{k}\left(P E C_{k} \cdot F M B_{k}\right)
$$

where $P V F_{n}$ is the present value factor of future cash flow at year $n$.

The economic viability of the SDHS can be specified as well based on the payback period [20]. It is widely used for evaluating energy system performance throughout its lifetime, and it's usually expressed in years. The shorter the payback period, the more favorably a project is ensured. The computation of the payback period can be obtained by dividing the future system value $(N P C)$ by the yearly cost saving for using the SDHS as follows:

$$
\text { Payback period }=\frac{N P C}{\text { Annual cost saving }}
$$

\section{Optimization problem}

The goal of the optimization was to minimize both the usage for auxiliary heater share $\left(A U X_{\text {share }}\right)$ and life cycle cost $(N P C)$. The problem was defined as:

$$
\begin{aligned}
& \min \left\{f_{1}(x), f_{2}(x)\right\} \\
& \text { s.t. } h(x)=0 \\
& \quad g(x) \geq 0 \\
& l b_{i} \leq x_{i} \leq u b_{i} \quad i \in\{1, \ldots, 15\}
\end{aligned}
$$

where $f_{1}$ is the $A U X_{\text {share }}, f_{2}$ is the life cycle cost, $h$ donates for the equality constraints, which corresponding to the mass and energy balance equation solved implicitly in TRNSYS in the first stage, $g$ is the limit on solar collector efficiency and seasonal storage efficiency. While $I b_{i}$ and $u b_{i}$ are the lower and upper bounds for all decision variables. The decision variables are introduced in Table I.

Three different community sizes were used: 10, 25, and 50 buildings. A separate optimization was performed for each community size. Optimization was performed with the MATLAB, through using a genetic algorithm. Population size was 500, and a Pareto fraction of 0.6. Additional calculations during optimization were performed with MATLAB. 
TABLE I. DECISION VARIABLES FOR THE SHDS CATEGORIZED BY CIRCUIT NAME

\begin{tabular}{|c|c|c|c|}
\hline Circuit name & Decision variable & Unit & Uniform \\
\hline \multirow{4}{*}{$\begin{array}{c}\text { Solar field } \\
\text { circuit }\end{array}$} & $\mathrm{A}_{\mathrm{COL}}$ (Col. area) & $\mathrm{m}^{2} / \mathrm{MWh} / \mathrm{a}$ & $0.1: 2$ \\
\cline { 2 - 4 } & $\beta_{\mathrm{COL}}$ (Inclination ang.) & $\circ$ & $20: 70$ \\
\cline { 2 - 4 } & $\mathrm{N}_{\mathrm{COL}}$ (No. Col. in series) & - & $1: 5$ \\
\hline \multirow{3}{*}{$\begin{array}{c}\text { SH distribution } \\
\text { circuit }\end{array}$} & $\mathrm{V}_{\mathrm{SST}}$ (SST vol.) & $\mathrm{m}^{3} / \mathrm{MWh} / \mathrm{a}$ & $1: 20$ \\
\cline { 2 - 4 } & $\mathrm{HDR}$ (Height to dia.) & $\mathrm{m} / \mathrm{m}$ & $0.3: 1.5$ \\
\cline { 2 - 4 } & $\mathrm{FC}_{\mathrm{AUX}-\mathrm{BH}}$ & $\%$ & $0.1: 1$ \\
\hline \multirow{3}{*}{$\begin{array}{c}\text { DHWW } \\
\text { distribution } \\
\text { circuit }\end{array}$} & $\mathrm{V}_{\mathrm{DHWT}}$ (DHW vol.) & $\mathrm{m}^{3} / \mathrm{MWh} / \mathrm{a}$ & $0.05: 0.25$ \\
\cline { 2 - 4 } & $\mathrm{HDR}_{\mathrm{DHWT}}($ Height to dia.) & $\mathrm{m} / \mathrm{m}$ & $1: 2$ \\
\cline { 2 - 4 } & $\mathrm{FC}_{\mathrm{AUX}-\mathrm{BDHW}}$ & $\%$ & $0.1: 1$ \\
\hline
\end{tabular}

\section{CASE STUDY}

A SDHS located in Madrid (Spain) is considered to meet the heating demand of different sized neighbourhood community (10, 25, and 50 buildings). Each building comprises 28 apartments with $90 \mathrm{~m}^{2}$ of useful area [21] per apartment and equipped with a radiant underfloor heating system and a domestic hot water system to meet the space heating and DHW demand at $50^{\circ} \mathrm{C}$ and $60^{\circ} \mathrm{C}$, respectively. Each building has a demand of $191.34 \mathrm{MWh} /$ year. The SDHS model validation and heating demand comparison were implemented in comparison to Guadalfajara et al. [22] and Tulus et al. [11].

\section{A. Economic inputs}

The parameters for the initial investment cost are outlined Following Tulus et al. [19], the maintenance cost is estimated to be $1.5 \%$ of the initial purchase cost of the equipment. The prices of natural gas and electricity are 0.0526 and 0.1873 Euro/kWh, respectively, based on the EUROSTAT database [23]. Moreover, the inflation rate associated with natural gas and electricity is $5.9 \%$ and 5\%, respectively [11]. According to Braungardt et al. [24], the inflation rate associated with the proposed system throughout its lifetime is set to be $2.3 \%$, with a discount rate of $3.5 \%$.

\section{RESULTS AND DISCUSSION}

\section{A. Optimization results}

The results examine the community size effect $(10,25,50$, and 100 buildings) on the performance of the SDHS in a techno-economic optimization framework. The results of optimization for all community sizes are shown in Fig. 2. A clear tendency between the objective functions and the increment in the community size, where increasing the community size from 10 to 50 buildings, the share of solar energy increases with the increment in the total SDHS cost.

Starting from the Min.cost-optimal solutions, the NPC is improved from 73.19 Euro/MWh at community size of 10 buildings to 53.7 Euro/MWh at 50 buildings. While in the

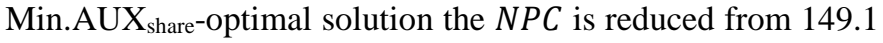
Euro/MWh at community size of 10 buildings to 87.4 Euro/MWh at community size of 50 Buildings. On the other hand, a slide improvement is achieved in the $A U X_{\text {share }}$ objective with an increment in the community size where $A U X_{\text {share }}$ is $16.7 \%, 16.6 \%$ and $16.1 \%$ for the community sizes of 10,25 and 50 , respectively at the Min cost solutions. While

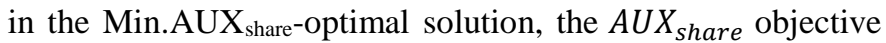
is below $1 \%$ for all community sizes.

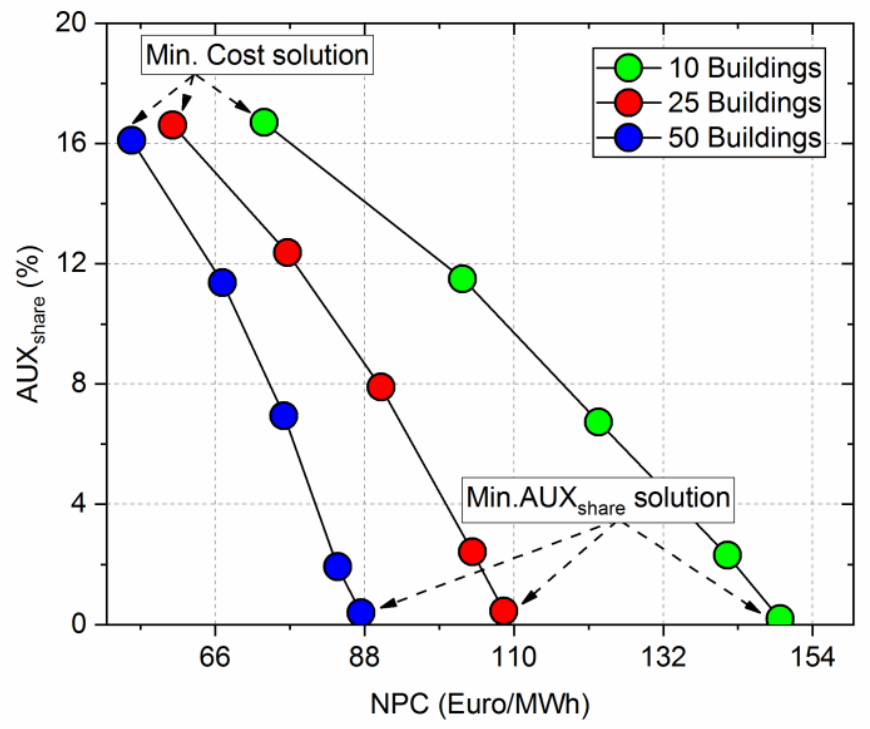

Fig. 2. Pareto sets for optimal SDHS solutions for different buildings sizes located in Madrid

TABLE II. THE OPTIMAL RANGE FOR THE DECISION VARIABLES OF THE SHDS CATEGORIZED BY CIRCUIT NAME AT DIFFERENT URBAN COMMUNITY SIZES

\begin{tabular}{|c|c|c|c|c|}
\hline & \multirow{2}{*}{\multicolumn{3}{|c|}{ Community Size }} \\
\hline & & & & \\
\hline $\begin{array}{c}\text { Circuit } \\
\text { name }\end{array}$ & $\begin{array}{l}\text { Decision } \\
\text { variable }\end{array}$ & 10 & 25 & 50 \\
\hline \multirow{3}{*}{$\begin{array}{l}\text { Solar field } \\
\text { circuit }\end{array}$} & $\begin{array}{c}\mathrm{A}_{\mathrm{COL}} \\
\left(\mathrm{m}^{2} / \mathrm{MWh} / \mathrm{a}\right)\end{array}$ & $\begin{array}{c}0.43: 1.3 \\
5 \\
\end{array}$ & $0.39: 1.20$ & $0.43: 1.15$ \\
\hline & $\beta_{\mathrm{COL}}$ (degree) & $44: 50$ & $42.3: 49.3$ & $41.6: 47.8$ \\
\hline & $\mathrm{N}_{\mathrm{COL}}$ & 4 & 4 & 4 \\
\hline \multirow{3}{*}{$\begin{array}{c}\text { Space } \\
\text { heating } \\
\text { distribution } \\
\text { circuit }\end{array}$} & $\begin{array}{c}\mathrm{V}_{\mathrm{SST}} \\
\left(\mathrm{m}^{3} / \mathrm{MWh} / \mathrm{a}\right)\end{array}$ & $2.5: 12.7$ & $3.04: 12.5$ & $3.6: 12.8$ \\
\hline & $\operatorname{HDR}(\mathrm{m} / \mathrm{m})$ & $\begin{array}{c}0.66: 0.7 \\
9 \\
\end{array}$ & 0.69:0.78 & $0.62: 0.73$ \\
\hline & $\mathrm{FC}_{\mathrm{AUX}-\mathrm{BH}}(\%)$ & $10: 60$ & $10: 14$ & $10: 14$ \\
\hline \multirow{3}{*}{$\begin{array}{c}\text { DHW } \\
\text { distribution } \\
\text { circuit }\end{array}$} & $\begin{array}{c}\mathrm{V}_{\text {DHWT }} \\
\left(\mathrm{m}^{3} / \mathrm{MWh} / \mathrm{a}\right)\end{array}$ & $\begin{array}{c}0.11: 0.1 \\
6 \\
\end{array}$ & $0.11: 0.24$ & $0.12: 0.19$ \\
\hline & $\operatorname{HDR}_{\text {DHWT }}(\mathrm{m} / \mathrm{m})$ & $1.3: 1.9$ & $1.30: 1.69$ & $1.4: 1.74$ \\
\hline & $\mathrm{FC}_{\mathrm{AUX}-\mathrm{BDHW}}(\%)$ & $22: 47.3$ & $11: 75.6$ & $32.3: 41$ \\
\hline
\end{tabular}

Following the optimal solution at different urban community sizes, Table II offers a complete depiction of the features and configurations for the optimal Pareto solutions categorized by the circuit at different community sizes.

In the solar circuit, most of the optimal Pareto solutions at different community sizes remain the $\mathrm{A}_{\mathrm{COL}}$ range between $0.4 \pm$ $0.05 \mathrm{~m}^{2} / \mathrm{MWh} / \mathrm{a}$ for the Min.cost solutions and extend to $1.2 \pm$ 


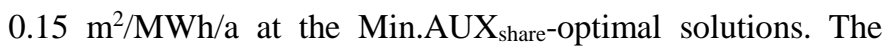
optimal inclination angles of the solar collectors $\left(\beta_{\mathrm{COL}}\right)$ stayed at an angle of $45 \pm 4^{\circ}$ for most of the community sizes, which is close to the latitude of Madrid. Moreover, the number of solar collectors connected in series remains at 4 for all optimal solutions. In the space heating circuit, the optimal characteristics of the SST at various community sizes show that the VSST is around $2.5 \pm 0.5 \mathrm{~m}^{3} / \mathrm{MWh} / \mathrm{a}$ at the Min.cost solutions, and it extends to $12.5 \pm 0.2 \mathrm{~m}^{3} / \mathrm{MWh} / \mathrm{a}$ at the Min.AUX $\mathrm{A}_{\text {share-optimal }}$ solutions, whereas the HDR is around $0.7 \pm 0.05 \mathrm{~m} / \mathrm{m}$ for all optimal solutions.

In the solar circuit, most of the optimal Pareto solutions at different community sizes remain the $\mathrm{A}_{\mathrm{COL}}$ range between $0.4 \pm$ $0.05 \mathrm{~m}^{2} / \mathrm{MWh} / \mathrm{a}$ for the Min.cost solutions and extend to $1.2 \pm$ $0.15 \mathrm{~m}^{2} / \mathrm{MWh} / \mathrm{a}$ at the Min.AUX share-optimal solutions. The optimal inclination angles of the solar collectors $\left(\beta_{\mathrm{COL}}\right)$ stayed at an angle of $45 \pm 4^{\circ}$ for most of the community sizes, which is close to the latitude of Madrid. Moreover, the number of solar collectors connected in series remains at 4 for all optimal solutions. In the space heating circuit, the optimal characteristics of the SST at various community sizes show that the $\mathrm{V}_{\text {SST }}$ is around $2.5 \pm 0.5 \mathrm{~m}^{3} / \mathrm{MWh} / \mathrm{a}$ at the Min.cost solutions, and it extends to $12.5 \pm 0.2 \mathrm{~m}^{3} / \mathrm{MWh} / \mathrm{a}$ at the Min.AUX $\mathrm{X}_{\text {share-optimal }}$ solutions, whereas the HDR is around $0.7 \pm 0.05 \mathrm{~m} / \mathrm{m}$ for all optimal solutions.

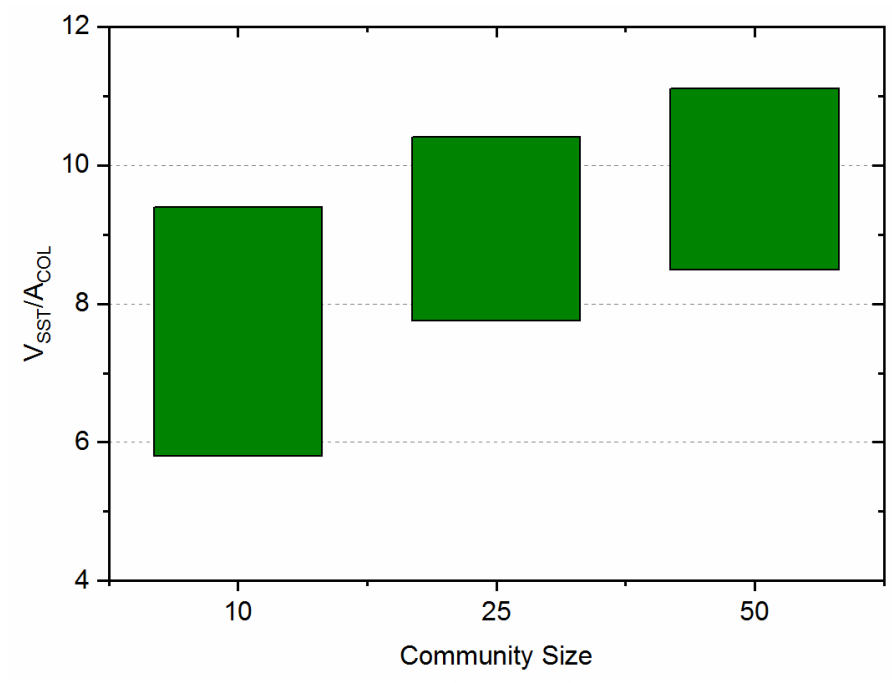

Fig. 3. The Seasonal storage tank volume to solar collector area ratio at different community sizes

In addition, Fig. 3 shows a summary for the proposed sizing of the $\mathrm{A}_{\mathrm{COL}}$ and $\mathrm{V}_{\mathrm{SST}}$ based on the Pareto optimal solution at various community sizes. With the increment in the community size, the upper and lower limits of the Pareto frontier solution increase where lower bounds are $5.6,7.7$ and $8.4 \mathrm{~m}^{3} / \mathrm{m}^{2}$ for the community size of 10, 25 and 50 building, respectively, Whereas the upper limits increase from 9.3 to $11.1 \mathrm{~m}^{3} / \mathrm{m}^{2}$ at investigated community sizes. In the DHW circuit, since the DHWT is used only for the daily purposes without long term storage, the histogram depicts that the $\mathrm{V}_{\mathrm{DHWT}}$ is only around $0.15 \pm 0.06 \mathrm{~m}^{3} / \mathrm{MWh} / \mathrm{a}$ for most of the optimal solutions, whereas the $\mathrm{HDR}_{\mathrm{DHWT}}$ diverge around $1.5 \pm 0.2 \mathrm{~m} / \mathrm{m}$.

\section{B. Economic performance}

Following the Pareto optimal solutions at different community sizes, Fig. 4 depicts a detailed breakdown for the life cycle cost of the SDHS when introduced at different community sizes under the extreme scenarios (Min.cost-optimal solutions $\&$ Min.AUX $X_{\text {share-optimal solutions). The initial investment cost }}$ at all other community sizes is a quite significant cost component compared to operation and the replacement cost. This cost contribution is ascending increases with reducing the AUX $_{\text {share }}$. In the Min.cost-optimal solutions, the investment cost represents $50.2 \%, 47.6 \%$ and $46.7 \%$ for the community size of 10,25 and 50 buildings, respectively. While in the

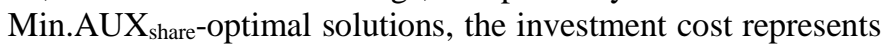
around $63 \%$ for all community sizes. To be more specific, the solar collector and SST have the main contribution to the initial investment cost.

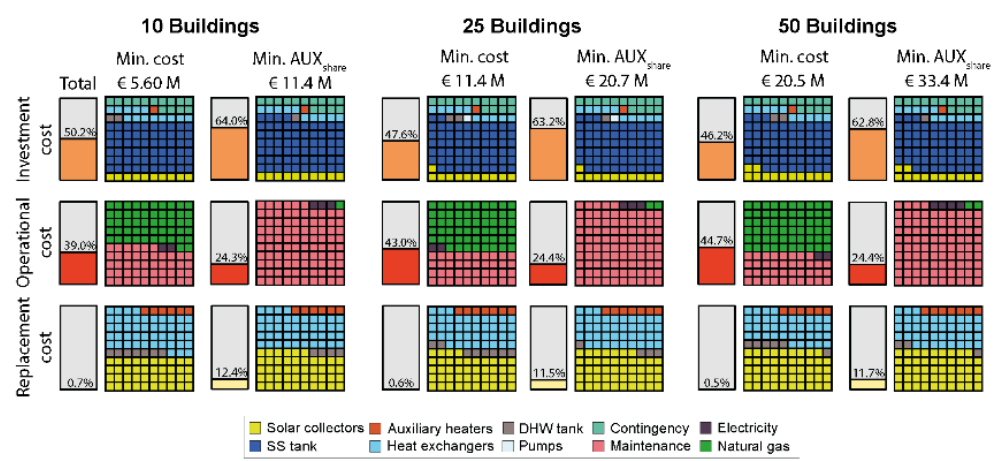

Fig. 4. Life cycle cost breakdown of Pareto optimal solutions for a SDHS system applied at various community sizes. The breakdown includes the shares of initial capital cost, operational cost, and replacement cost

On the other hand, the operational cost declines with the movement toward the Min.AUX share-optimal solution where it represents 39\%, $43 \%$ and $44.7 \%$ for the community size of 10 , 25 and 50 buildings, respectively. Moreover, it declines to around $24 \%$ in the Min.AUX $X_{\text {share-optimal solutions, which }}$ implies the less usage of natural gas. To be more specific, the auxiliary heaters represents above $50 \%$ of the total operational cost in each community size at the Min.cost-optimal solutions, and it is reduced to around $1 \%$ for Min.AUX $\mathrm{X}_{\text {share-optimal }}$ solutions. The replacement cost follows the same trends as the investment cost, where it represents about $0.5 \%$ in the Min.costoptimal solutions, and it increases to around $12 \%$ in

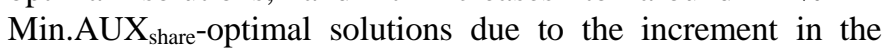
share of renewable energy equipment.

In addition to the economic breakdown, the payback period is proposed to measure the system feasibility throughout its lifetime, as shown in Fig. 5. the SDHS could not approve its feasibility in the community size of 10 buildings since it varies between 39.4 years and 66.6 years, which is higher than the lifetime of the SDHS. With increasing the community size, the payback period decreases progressively, where the payback period at the Min.AUX $\mathrm{X}_{\text {share-optimal solution reduces to } 32.2 \text {, and }}$ 28.8 years for the community size of 25 , and 50 buildings, respectively. 


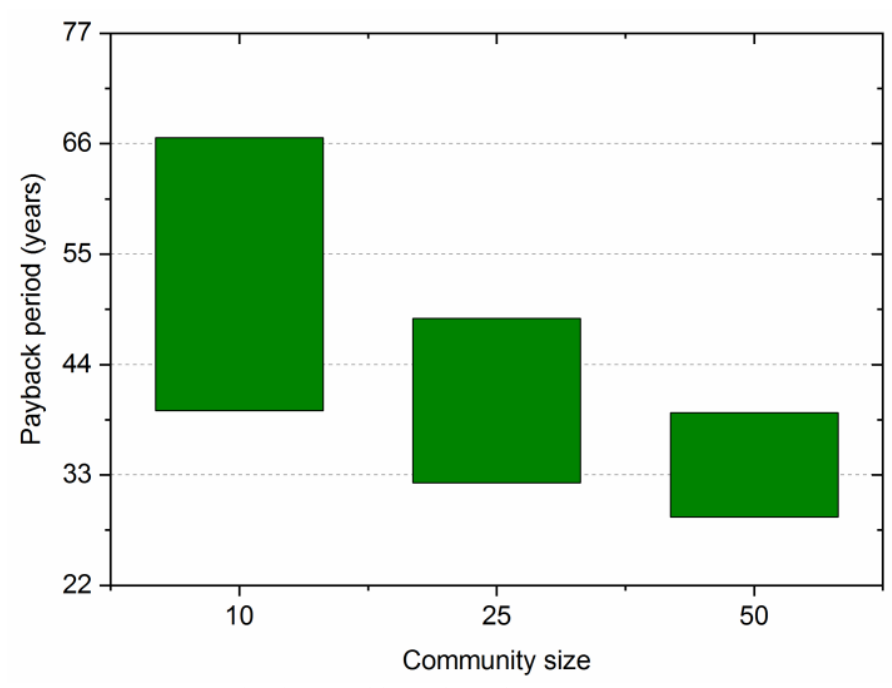

Fig. 5. Payback period bounds at different community sizes

(a)

(b)
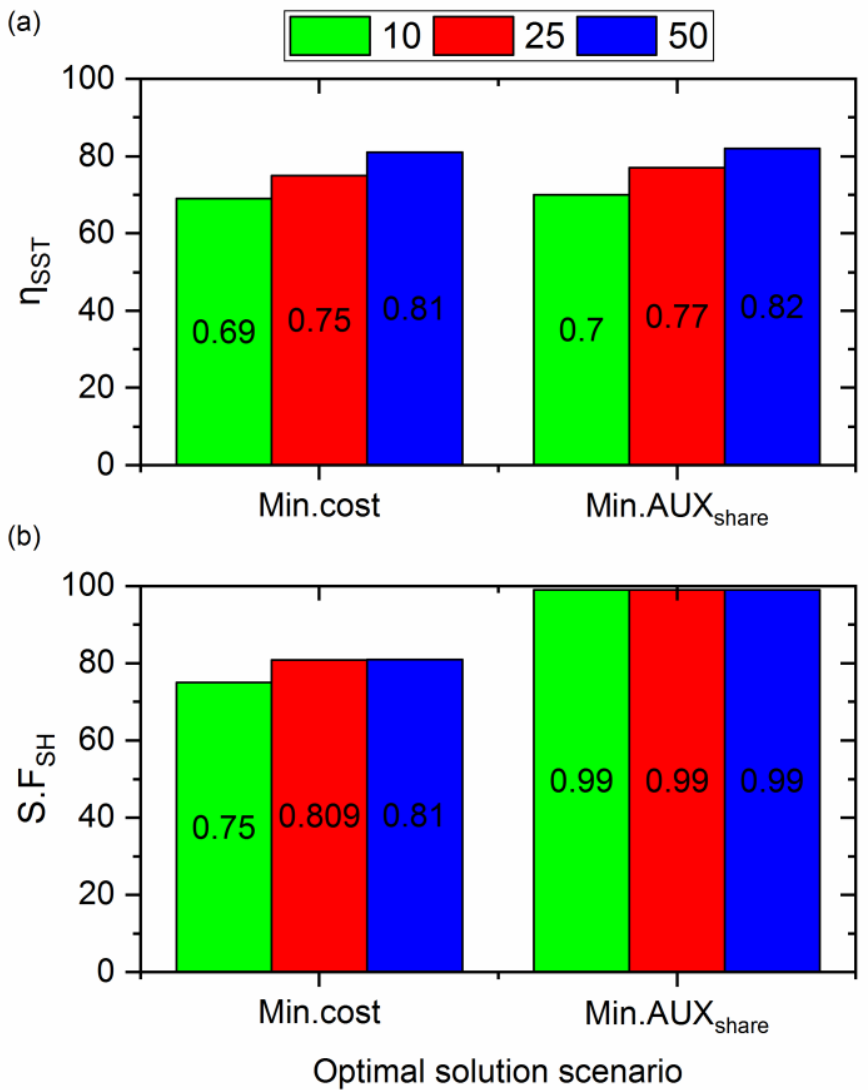

Fig. 6. The performance indicator including (a) $\eta_{S S T}$, (B) S. $F_{S H}$ for the optimal Pareto SDHS solutions at different community size of 10, 25 and 50 buildings

\section{Thermal performance}

Finally, our methodology facilitates the analysis of the optimal configurations of a SDHS from the thermodynamic point of view based on the $\eta_{\text {SST }}$ and $S . F_{S H}$ as shown in Fig. 6. In term of the $\eta_{S S T}$, the SST efficiency rises with reducing the
AUX $X_{\text {share }}$ where the $\eta_{\text {SST }}$ in the Min.cost-optimal solution is $69 \%, 75.0 \%$, and $81 \%$ for the community sizes of 10,25 , and 50 buildings, respectively. Moreover, this value increases slightly

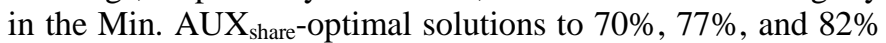
for the community size of 10,25 , and 50 buildings, respectively. While in terms of the $S . F_{S H}$, a value of $75 \%$ is indicated for a community size of 10 buildings. This value can be improved with the increment in the community size where $S . F_{S H}$ of $80.9 \%$, and $82 \%$ is indicated for the community size of 25 and 50 buildings. With the movement toward the Min. AUX $X_{\text {share }}$ solutions, all optimal cases show that the $S . F_{S H}$ closes to $100 \%$. On the other hand, the $S . F_{D H W}$ never falls below $98 \%$ for all community sizes.

\section{CONCLUSION}

In this study, a multi-objective optimization methodology is presented to evaluate the techno-economic feasibility of the SDHS at different urban communities located in Madrid; these residential communities include 10,25 , and 50 buildings. The main finding of this work is that the SDHS can bring both technical and economic benefits simultaneously, especially in the large the communities of 50 buildings. A summary for methodology key findings is the following:

- The Min.cost-optimal solutions demonstrate progressive improvement in the economic benefits of the SDHS with the increment in the community sizes where the $N P C$ is improved by $19.1 \%$, and $27.3 \%$ for community size of 25 , and 50 buildings, respectively. While Min.AUX optimal solution, this improvement can extend to $27.5 \%$ and $41.6 \%$ for the 25 and 50 buildings, respectively.

- This improvement can be reflected in the payback period where it around 40 years for the community of 10 buildings, and it can be reduced to 32.2 and 29 years for the community size of 25 and 50 buildings.

- From the thermal point of view, the $\eta_{S S T}$ in the Min.cost-optimal solution is $69 \%, 75.0 \%$, and $81 \%$ for the community sizes of 10,25 , and 50 buildings. Moreover, it can expand up to $82 \%$ in the community size of 50 buildings. While in terms of the $S . F_{S H}$, it never falls below $75 \%$ for all community sizes.

In general, this study has shown that SHDS can provide a significant contribution to the energy demand at the residential section, especially in large communities. However, more realized projects are needed to generate practical experience on system design and operation and to lower costs through increased market activity.

\section{ACKNOWLEDGMENT}

The work is funded by the Spanish government RTI2018093849-B-C31 and RTI2018-093849-B-C33. The authors would like to thank the Catalan Government for the quality accreditation given to their research group (GREiA - 2017 SGR 1537, AGACAPE - 2017 SGR 1409). GREiA is a certified agent TECNIO in the category of technology developers from the Government of Catalonia. This work is partially supported by 
ICREA under the ICREA Academia programme. This work is partially funded by the Ministerio de Ciencia, Innovación y Universidades - Agencia Estatal de Investigación (AEI) (RED2018-102431-T). This project has received funding from the European Union's Horizon 2020 research and innovation programme under the Marie Skłodowska-Curie grant agreement No. 713679 and from the Universitat Rovira i Virgili (URV).

\section{REFERENCES}

[1] Balaras, C. A., Gaglia, A. G., Georgopoulou, E., Mirasgedis, S., Sarafidis, Y., and Lalas, D. P., 2007, "European Residential Buildings and Empirical Assessment of the Hellenic Building Stock, Energy Consumption, Emissions and Potential Energy Savings," Build. Environ., 42(3), pp. 1298-1314.

[2] Eurostat, 2016, "Final Energy Consumption in the Residential Sector by Type of End-Use" [Online]. Available: https://ec.europa.eu/eurostat/statisticsexplained/index.php?title=File:Final_energy_consumption_in_the_r esidential_sector_by_type_of_end-use,_EU-

28,_2015.png\&oldid=340063. [Accessed: 27-Jun-2019].

[3] Modi, A., Bühler, F., Andreasen, J. G., and Haglind, F., 2017, "A Review of Solar Energy Based Heat and Power Generation Systems," Renew. Sustain. Energy Rev., 67, pp. 1047-1064.

[4] Hirvonen, J., Kayo, G., Hasan, A., and Sirén, K., 2016, “Zero Energy Level and Economic Potential of Small-Scale Building-Integrated PV with Different Heating Systems in Nordic Conditions," Appl. Energy, 167, pp. 255-269.

[5] Bauer, D., Marx, R., and Drück, H., 2014, "Solar District Heating for the Built Environment Technology and Future Trends within the European Project Einstein," Energy Procedia, 57(0), pp. 2716-2724.

[6] Xu, J., Wang, R. Z., and Li, Y., 2014, "A Review of Available Technologies for Seasonal Thermal Energy Storage," Sol. Energy, 103, pp. 610-638.

[7] Hirvonen, J., ur Rehman, H., and Sirén, K., 2018, “Techno-Economic Optimization and Analysis of a High Latitude Solar District Heating System with Seasonal Storage, Considering Different Community Sizes," Sol. Energy, 162(April 2017), pp. 472-488.

[8] Reuss, M., 2015, Advances in Thermal Energy Storage Systems: Methods and Applications, Woodhead Publishing Limited, United Kingdom.

[9] Bankston, C. A., 1988, "The Status and Potential of Central Solar Heating Plants with Seasonal Storage: An International Report," Advances in Solar Energy, Plenum Press, New York, pp. 352-444.

[10] Weiss, W., Spörk-Dür, M., and Mauthner, F., 2017, Solar Heat Worldwide: Global Market Development and Trends in 2016, Gleisdorf, Austria.

[11] Tulus, V., Abokersh, M. H., Cabeza, L. F., Vallès, M., Jiménez, L., and Boer, D., 2019, "Economic and Environmental Potential for
Solar Assisted Central Heating Plants in the EU Residential Sector: Contribution to the 2030 Climate and Energy EU Agenda," Appl. Energy.

[12] Bauer, D., Marx, R., and Nußbicker-Lux, J., 2010, "German Central Solar Heating Plants with Seasonal Heat Storage," Sol. Energy, 84(4), pp. 612-623.

[13] Reuss, M., Beuth, W., Schmidt, M., and Schoelkopf, W., 2006, "Solar District Heating with Seasonal Storage in Attenkirchen," Proc. IEA Conf. ECOSTOCK, Richard Stock. Coll. Pomona, New Jersey, USA.

[14] Lund, P. D., 1984, "Optimization of a Community Solar Heating System with a Heat Pump and Seasonal Storage," Sol. Energy, 33(34), pp. 353-361.

[15] Sibbitt, B., McClenahan, D., Djebbar, R., Thornton, J., Wong, B., Carriere, J., and Kokko, J., 2012, "The Performance of a High Solar Fraction Seasonal Storage District Heating System - Five Years of Operation," Energy Procedia, 30, pp. 856-865.

[16] Weiss, W., Spörk-Dür, M., and Mauthner, F., 2017, Solar Heat Worldwide: Global Market Development and Trends in 2016, Gleisdorf, Austria.

[17] Rehman, H. ur, Hirvonen, J., and Sirén, K., 2018, "Influence of Technical Failures on the Performance of an Optimized CommunitySize Solar Heating System in Nordic Conditions," J. Clean. Prod., 175, pp. 624-640.

[18] TRNSYS, "A Transient System Simulation Program."

[19] Tulus, V., Boer, D., Cabeza, L. F., Jiménez, L., and GuillénGosálbez, G., 2016, "Enhanced Thermal Energy Supply via Central Solar Heating Plants with Seasonal Storage: A Multi-Objective Optimization Approach,” Appl. Energy, 181, pp. 549-561.

[20] Vikas, K., Cheshta, K., Savita, N., and Baredar, P., 2019, "Prefeasibility Assessment of a Tidal Energy System," Tidal Energy Systems Design, Optimization and Control, Elsevier, pp. 115-188.

[21] Institute for Energy Diversification and Saving - IDAE, 2011, Análisis Del Consumo Energético Del Sector Residencial En España. INFORME FINAL;

[22] Guadalfajara, M., 2013, "Evaluación de Centrales Solares Térmicas Con Acumulación Estacional Para El Sector Residencial En España."

[23] European Commision, 2018, "EuroStat" [Online]. Available: http://ec.europa.eu/eurostat/web/energy/data/database. [Accessed: 12-Mar-2018]

[24] Braungardt, S., Eichhammer, W., Elsland, R., Fleiter, T., Klobasa, M., Krail, M., Pfluger, B., Reuter, M., Schlomann, B., Sensfuss, F., and Sohaib, T., 2014, Study Evaluating the Current Energy Efficiency Policy Framework in the EU and Providing Orientation on Policy Options for Realising the Cost-Effective Energy-Efficiency/Saving Potential until 2020 and Beyond. 